\title{
PERBANDINGAN SOSIAL DAN EMOSI ANAK USIA PRASEKOLAH YANG MENGIKUTI DAN TIDAK MENGIKUTI PENDIDIKAN ANAK USIA DINI
}

\author{
Asmarita $^{1}$, Hamid Abdurrahman ${ }^{2}$, Utami Agnita $^{3}$ \\ ${ }^{1}$ Program Studi Keperawatan STIKes Hangtuah Pekanbaru
}

Korespondensi: asmarita034@gmail.com

\begin{abstract}
Background: Social and emotional development of young children is affected by many stimulating factors, and one of those factors is early childhood education however, not all preschool children have the opportunity to attend early childhood education. This study was aimed at comparing children's social and emotional development of those who attend and do not attend early childhood education. Method: This comparative study was carried out using cross sectional approach among 72 participants divided into 2 groups: 36 participants who attend early childhood education and 36 participants who do not attend early childhood education. Consecutive sampling technique was applied to select samples. Results: Nonparametric statistical test employed was Mann Whitney test, whose comparison value of children attending and not attending early childhood education was $\mathrm{P}_{\text {value }} 0.000$; the emotional comparison value was $\mathrm{P}_{\text {value }} 0.040$, so it can be concluded that there were differences in social and emotional development between children who attend early childhood education and those who do not attend early childhood education. Conclusion: Early childhood education can help stimulate development on children. Parents should pay more attention to their children's social and emotional development, whereas if parents cannot be the medium to support children's social and emotional development, they should engage their children to early childhood education.
\end{abstract}

Keywords: Pre-schoolers, early childhood education, social and emotional development

\begin{abstract}
ABSTRAK
Latar Belakang : Pertumbuhan perkembangan sosial dan emosi anak dipengaruhi oleh banyak faktor untuk menstimulasinya, PAUD merupakan salah satu faktor yang dapat membantu menstimulasi perkembangan sosial dan emosi anak, tetapi tidak semua anak mengikuti PAUD. Tujuan penelitian ini yaitu untuk membandingkan perkembangan sosial dan emosi anak mengikuti dan tidak mengikuti PAUD. Metode: Penelitian ini menggunakan desain survey Comparative Study dengan pendekatan cross sectional. Jumlah sampel pada penelitian 72 responden yang dibagi menjadi 36 mengikuti dan 36 tidak mengikuti PAUD. Pengambilan sampel dengan teknik Consecutive Sampling. Hasil: Uji statistik yang digunakan adalah uji non-parametrik yaitu Mann Whitney test, dengan hasil perbandingan sosial anak mengikuti dan tidak mengikuti PAUD $P_{\text {value }} 0,000$, perbandingan emosi didapatkan $P_{\text {value }} 0,040$, dapat disimpulkan terdapat perbedaan perkembangan sosial dan emosi anak yang mengikuti dan tidak mengikuti PAUD. Simpulan: Pendidikan anak usia dini dapat membantu menstimulasi perkembangan anak. Sebagai orang tua harus lebih baik dalam memperhatikan perkembangan sosial dan emosi anak, ketika orang tua tidak bisa menjadi tempat perkembangan sosial dan emosi anak, orang tua dapat mengikutsertakan anak ke pendidikan anak usia dini.
\end{abstract}

Kata Kunci: anak usia prasekolah, pendidikan anak usia dini, perkembangan sosial dan emosi 


\section{PENDAHULUAN}

Anak merupakan bagian dari keluarga dan juga masyarakat, individu yang berada pada suatu rentang tumbuh kembang anak yang berusia 3-6 tahun, pada usia ini perhatian dan bimbingan dari orang tua dan orang disekitarnya sangat dibutuhkan. Saat usia prasekolah ini anak memiliki perkembangan biologis, psikologis, kognitif, moral spritual, dan sosial serta emosi yang akan mempengaruhi tumbuh kembang anak selanjutnya (Rekawati, Nursalam \& Sri, 2013). Anak usia prasekolah belum masuk suatu lembaga pendidikan formal seperti Sekolah Dasar (SD), biasanya anak usia prasekolah tetap berada dirumah atau mengikuti kegiatan diluar rumah seperti : kelompok bermain, taman kanak-kanak serta taman penitipan anak (Nurmalitasari, 2015).

Berdasarkan data badan Statistik Amerika Serikat jumlah penduduk dunia mencapai 7,53 miliar jiwa dan jumlah anak usia prasekolah sekitar 8,7\% dari total populasi tersebut. Jumlah anak prasekolah di Indonesia mencapai 24 juta jiwa, dan di propinsi Riau berjumlah 583.450 jiwa (Kemenkes RI 2017). Penduduk usia prasekolah di Pekanbaru berjumlah 106.749 jiwa (BPS, 2017), dari data tersebut bisa dilihat banyaknya generasi-generasi penerus yang diharapkan mampu menjadi pemimpin serta menjadi individu yang mempunyai moral dan perilaku yang baik.

Perkembangan anak tidak selamanya berjalan dengan baik, namun sering teradapat kendala dalam menyelesaikan tugas perkembangan anak di usia prasekolah sehingga menyebabkan timbulnya masalah pada usia remaja seperti antisosial, agresif, serta melakukan tindakan-tindakan kriminal (Hull \& Johnston, 2008). Anak mampu mencapai kompetensi sosial dengan baik sehingga dapat membantu anak dalam interaksi sosial dengan tetap menjaga hubungan positif dengan orang lain dalam berbagai situasi (Musyarofah, 2017). kematangan anak dalam bersosialisasi sangat besar peranannya, terutama dalam pertemanan anak, kesiapan anak untuk sekolah dan keberhasilan akademik anak (Anggereini, 2012).

Masalah sosial yang sering muncul pada anak usia prasekolah yaitu perilaku takut yang berlebihan seperti takut akan perpisahan, takut dengan orang baru dan perilaku menarik diri yang digambarkan anak seperti tidak mau bersosialisasi, menyendiri, tidak mau bermain dengan anak lainnya, sibuk dengan mainanya sendiri. Perilaku tersebut bisa disebabkan dari faktor lingkungan yang kurang mendorong serta memberi stimulasi anak untuk bersosialisasi, agar perilaku tersebut tidak dialami anak perlunya orang tua serta lingkungan dalam mempertimbangkan serta memberikan kasih sayang dan perhatian yang lebih pada anak, 
meluangkan waktu untuk anak, menjadi pendengar yang baik, melibatkan diri dalam aktivitas anak, menjaga sikap terhadap anak (Ashary, Rahamma \& Fatimah, 2015). Masalah sosial pada anak seperti Maladjustment yaitu penyesuain diri dengan lingkungan baru juga sering terjadi serta anak yang merasa puas terhadap tingkah lakunya namun lingkungan sosial tidak bisa menerima, misalnya anak yang mempunyai perilaku bossy, sok kuasa, anak tersebut merasa tidak salah namun lingkungan sekitar merasa terganggu dengan perilakunya tersebut (Tirtayani, Asril \& Wirya, 2014).

Berdasarkan peneliti sebelumnya yang dilakukan oleh Khomairah (2012) didapatkan permasalahan pada tingkat sosial anak usia prasekolah yaitu 60,5\% rendah, untuk komponen otonomi $52,6 \%$, komponen responsif $42,1 \%$, sedangkan komponen empati $31,6 \%$, motorik $50 \%$, dan regulasi emosi didapatkan 92,1\% level tinggi. Hariani (2015) melakukan penelitian tentang perkembangan sosial anak usia prasekolah dalam ketidak mampuan dalam bersosialisasi dengan orang lain atau teman sebayanya didapatkan 38,18\%. Al-Khudri, Heleni, Sean (2016) melakukan penelitian tentang tingkat emosi anak usia prasekolah dengan hasil yaitu anak mampu mengontrol emosinya dengan baik 30\%, mengontrol emosinya dalam ketegori sedang 20\%, dan anak yang tidak bisa mengontrol emosinya 50\%. Kematangan emosi anak yang baik akan berdampak baik seperti tidak cepat terganggu rangsangan emosionalnya, baik itu dari dalam maupun dari luar sehingga individu mampu bertindak dengan tepat sesuai dengan situasi dan kondisi, sebaliknya kematangan emosi yang rendah menyebabkan individu memiliki resiko melakukan kenakalan dan melakukan kekerasan dalam menyelesaikan masalah (Fajarini, Khaerani, 2014.)

Pendidikan Anak Usia Dini (PAUD) dapat membantu proses perkembangan sosial dan emosi anak menjadi lebih baik, pada hakikatnya PAUD merupakan pendidikan yang diselenggarakan dengan tujuan memfasilitasi pertumbuhan serta perkembangan anak secara menyeluruh, ditinjau dari aspek umur anak, meliputi perkembangan moral keagamaan, motorik, kognitif dan sosial-emosional (Aghnaita, 2017). Guru sangat berperan dalam membina anak serta teman sebaya yang berada dilingkungan pendidikan juga saling mempengaruhi serta saling mendukung dalam perkembangan sosial dan emsoi (Jahja, 2011). Tujuan penelitian ini adalah untuk mengetahui perbandingan sosial dan emosi anak usia prasekolah yang mengikuti dan tidak mengikuti pendidikan anak usia dini. 


\section{METODE}

Jenis penelitian kuantitatif ini menggunakan survey Comparative Study (studi perbandingan) dengan desain yang digunakan Cross Sectional. Populasi pada penelitian ini yaitu orang tua yang memiliki anak usia prasekolah program TK B di TK Negeri Pembina 3 Pekanbaru. Jumlah sampel pada penelitian ini berjumlah 72 responden dari 112 populasi. Jenis teknik sampling yang digunakan pada penelitian ini teknik Consecutive Sampling. Instrumen penelitian yang digunakan adalah Angket/kuesioner dengan cara Checklist. Peneliti kemudian melakukan pengolahan data melalui program komputer. Peneliti menganalisis data yang meliputi analisa univariat dan bivariat dengan uji Saphiro Wilk untuk uji normalitas dan menggunakan uji Statistik alternatif Mann Whitney test karena data yang telah didapatkan tidak berdistribusi normal.

\section{HASIL}

\section{Analisis Univariat}

Tabel 1 Distribusi Frekuensi Karakteristik Responden di TK Negeri Pembina 3 Pekanbaru Tahun 2019

\begin{tabular}{clcc}
\hline No & Karakteristik responden & f & $\%$ \\
\hline 1 & Jenis kelamin & & \\
& Laki - laki & 37 & $51,4 \%$ \\
& perempuan & 35 & $48,6 \%$ \\
2 & Jumlah saudara & & $55,6 \%$ \\
& Sedikit (1-2) & 40 & $44,4 \%$ \\
& Banyak (> 2) & 32 & $13,9 \%$ \\
Pekerjaan orang tua & & $6,9 \%$ \\
& PNS & 10 & $33,3 \%$ \\
& Guru & 24 & $13,9 \%$ \\
& Wiraswasta & 10 & $31,9 \%$ \\
& Pegawai & 23 & $100 \%$ \\
& IRT & 72 & \\
& Jumlah & & \\
& & &
\end{tabular}

Berdasarkan Tabel 1 diatas dapat diketahui bahwa dari 72 responden yang diteliti, distribusi frekuensi responden jenis kelamin mayoritas laki-laki sebanyak 37 orang (51,4\%). Distribusi jumlah saudara anak mayoritas sedikit (1-2 orang) berjumlah 40 orang (55,6 \%). Perekrjaan orang tua anak mayoritas sebagai wirasawta yaitu 24 orang $(33,3 \%)$.

\section{Usia responden}

Tabel 2 Distribusi Beradasarkan Usia Anak Prasekolah TK Negeri Pembina 3 Pekanbaru Tahun 2019

\begin{tabular}{ccccccc}
\hline usia & $\mathrm{n}$ & mean & median & SD & min & maks \\
\hline $5-6$ tahun & 72 & 5,85 & 6,00 & 0,362 & 5 & 6 \\
\hline
\end{tabular}


Berdasarkan Tabel 2 diatas dapat kita ketahui bahwa dari 72 responden pada penelitian ini didapatkan usia anak minimal 5 tahun dan usia anak maksimum 6 tahun, dengan nilai mean $=$ 5,85 .

\section{Perkembangan anak mengikuti paud}

Tabel 3 Distribusi Frekuensi Perkembangan Sosial Anak Mengikuti PAUD

\begin{tabular}{llcc}
\hline No & \multicolumn{1}{c}{ Perkembangan anak } & f & $\%$ \\
\hline 1 & Perkembangan sosial & & \\
& Sedang & 17 & $47,2 \%$ \\
& Tinggi & 19 & $52,8 \%$ \\
& Perkembangan emosi & & \\
& Kemungkinan ada masalah & 21 & $58,3 \%$ \\
& Tidak ada masalah Jumlah & 15 & $41,7 \%$ \\
& $\quad 36$ & $100 \%$ \\
\hline
\end{tabular}

Dari tabel 4 diatas didapatkan perkembangan sosial yang signifikan yaitu tinggi 19 orang $(52,8 \%)$ dan perkembangan sosial yang signifikan kemungkinan ada masalah 21 orang $(58,3 \%)$.

\section{Perkembangan anak tidak mengikuti paud}

Tabel 4 Distribusi Frekuensi Perkembangan Sosial dan Emosi Anak tidak Mengikuti PAUD

\begin{tabular}{llcc}
\hline No & \multicolumn{1}{c}{ Perkembangan anak } & $\mathrm{f}$ & $\%$ \\
\hline 1 & Perkembangan sosial & 31 & $86,1 \%$ \\
& Sedang & $31 \%$ & $13,9 \%$ \\
& Tinggi & 5 & \\
& Perkembangan emosi & & $63,1 \%$ \\
& Kemungkinan ada masalah & 23 & $36,1 \%$ \\
& Tidak ada masalah $\quad$ Jumlah & 13 & $100 \%$
\end{tabular}

Berdasarkan tabel 4 diatas didapatkan perkembangan sosial anak tidak mengikuti PAUD mayoritas sedang 31 orang $(86,1 \%)$ dan perkembangan emosi kemungkinan ada masalah 23 orang $(63,1 \%)$.

\section{Analisis Bivariat}

Setelelah dilakukan uji Saphiro Wilk didapatkan nilai perkembangan sosial anak dari kelompok yang mengikuti didapatkan nilai $\mathrm{P}_{\text {value }} 0,70$ dan tidak mengikuti PAUD didapatkan nilai $P_{\text {value }}$ 0,027 yang berarti ada data yang berdistribusi normal dan tidak berdistribusi normal, pada perkembangan emosi dari kelompok mengikuti PAUD dan tidak mengikuti PAUD didapatkan nilai $\mathrm{P}_{\text {value }}$ 0,000. Oleh karena itu, peneliti memutuskan menggunakan uji statistik nonparametrik, adapun uji non-parametrik yang digunakan yaitu Mann Whitney test. 


\section{Perbandingan sosial anak mengikuti dan tidak mengikuti PAUD}

Tabel 5 Perbandingan perkembangan sosial anak mengikuti dan tidak mengikuti PAUD di TK Negeri Pembina 3 Pekanbaru Tahun 2019

\begin{tabular}{cccccccc}
\hline Pendidikan & \multicolumn{4}{c}{ Perkembangan } & & Total & P \\
& \multicolumn{2}{c}{ Sedang } & \multicolumn{2}{c}{ Tinggi } & & & \\
\cline { 2 - 9 } & $\mathrm{f}$ & $\%$ & $\mathrm{f}$ & $\%$ & $\mathrm{f}$ & $\%$ & \\
PAUD & 17 & 47,2 & 19 & 52,8 & 36 & 100 & 0,000 \\
Tidak PAUD & 31 & 86,1 & 5 & 13,9 & 36 & 100 &
\end{tabular}

Berdasarkan Tabel 5 diatas memaparkan hasil uji Mann Whitney test didapatkan $P_{\text {value }}<0,05$ sehingga dapat diambil kesimpulan bahwa terdapat perbedaan perkembangan sosial anak yang mengikuti dan tidak mengikuti PAUD.

\section{Perbandingan emosi anak mengikuti dan tidak mengikuti PAUD}

Tabel 6 Perbandingan Perkembangan Emosi Anak Mengikuti dan tidak Mengikuti PAUD di TK Negeri Pembina 3 Pekanbaru Tahun 2019

\begin{tabular}{|c|c|c|c|c|c|c|c|}
\hline \multirow[b]{2}{*}{ Pendidikan } & \multicolumn{4}{|c|}{ Perkembangan } & \multirow{2}{*}{\multicolumn{2}{|c|}{ Total }} & \multirow[b]{2}{*}{$\mathrm{P}$} \\
\hline & \multicolumn{2}{|c|}{$\begin{array}{l}\text { Kemungkinan ada } \\
\text { masalah }\end{array}$} & \multicolumn{2}{|c|}{ Tidak ada masalah } & & & \\
\hline & $\mathrm{f}$ & $\%$ & $\mathrm{f}$ & $\%$ & f & $\%$ & \\
\hline PAUD & 21 & 58,3 & 15 & 41,7 & 36 & 100 & 0,040 \\
\hline Tidak PAUD & 23 & 63,1 & 13 & 36,1 & 36 & 100 & \\
\hline
\end{tabular}

Berdasarkan Tabel 6 diatas memaparkan hasil uji Mann Whitney test untuk perkembangan emosi anak didapatkan nilai $P_{\text {value }}<0,05$ yang artinya terdapat perbedaan yang signifikan antara perkembangan emosi anak yang mengikuti dan tidak mengikuti PAUD.

\section{PEMBAHASAN}

\section{Jumlah saudara}

Dari hasil penelitian di dapatkan responden yang memiliki jumlah saudara sedikit (1-2) yaitu 40 orang $(55,6 \%)$ dan banyak (>2) yaitu 32 orang (44\%). Penelitian Indanah \& Ningrum (2019) mengatakan jumlah saudara dapat berpengaruh terhadap perkembangan anak. Anak dengan jumlah saudara sedikit (1-2) orang lebih banyak mengalami permasalahan dalam perkembangan sosial dan emosi dibandingkan jumlah saudara yang banyak (>2). Jumlah saudara lebih sedikit atau sebagai anak tunggal dan tinggal bersama kedua orang tua saja, anak hanya lebih sering berinteraksi dengan sedikit orang, dan segala keinginan selalu terpenuhi sehingga anak akan kesulitan ketika anak berada diluar harus berinteraksi dengan banyak 
orang, anak juga akan kesulitan ketika anak harus berbagi dalam bermain atau berbagi makanan terhadap teman lainnya, karena anak terbiasa sendiri dan memiliki sepenuhnya dalam menikmati fasilitas permainan ataupun makanan yang diberikan oleh orang tuanya. Sari (2011) mengatakan jumlah saudara yang kecil cenderung menghasilkan perselisihan banyak dibanding jumlah saudara banyak. Namun terdapat interaksi lain antara kakak dan adik, sebagai kakak akan merasa iri kepada adik karena merasa mendapat perlakuan yang berbeda dari orang tua.

\section{Pekerjaan orang tua}

Penelitian yang dilakukan di TK N Pembina 3 Pekanbaru didapatkan PNS 10 orang (13,9\%), guru 5 orang $(6,9 \%)$, wiraswasta 24 orang $(33,3 \%)$, pegawai 10 orang $(13,9 \%)$ dan tidak bekerja/IRT 23 orang (31,9\%). Dari data tersebut dapat kita simpulkan bahwa orang tua lebih banyak bekerja $(68,1 \%)$ dan tidak bekerja/IRT (31,9\%). Ningrum \& Indanah (2019) mengatakan pola asuh sangat berpengaruh terhadap perkembangan sosial emosi anak, semakin banyak orang tua meluangkan waktu terhadap anaknya maka semakin banyak kesempatan anak untuk belajar terhadap orang tua karna orang tua merupakan role model bagi anak, anak mendapatkan kasih sayang penuh dan membangun komunikasi dengan baik (Sunarsih, 2018). Orang tua yang terlalu lama bekerja menyebabkan anak kurang mendapatkan perhatian dukungan serta kasih sayang yang lebih terhadap anak. Orang tua yang tidak bekerja sepenuhnya atau orang tua yang tidak bekerja akan lebih banyak memberikan waktu bersama sehingga mampu mengontrol kegiatan anak dan banyak mengajarkan tentang hal yang baik dan buruk. Sejak dini anak harus dilatih dalam berperilaku sosial dan mengelola emosi dengan baik sehingga perkembangan anak selanjutnya lebih baik.

\section{Perkembangan anak mengikuti PAUD}

\section{Perkembangan sosial}

Hasil penelitian perkembangan sosial anak mengikuti paud dengan jumlah sampel 36, didapatkan perkembangan sosial terdapat yang sedang 17 orang (47,2\%) dan tinggi 19 orang (52,8\%). Susanto (2011) dan Hurlock (2011) mengatakan perkembangan sosial pada anak usia prasekolah meliputi tingkah laku yang harus distimulasi yaitu kerja sama anak dengan anak lainnya, bertindak jujur seperti mengikuti aturan dalam permainan, keperdulian/kemurahan hati terhadap orang lain, berbagi dengan orang lain, berperilaku akrab dengan teman maupunn orang lain. Sesuai dengan pasal 1 ayat 14 Undang-undang Nomor 20 Tahun 2003, menyatakan pendidikan anak usia dini merupakan pelayanan yang ditujukan untuk kepada anak yang baru lahir hingga sampai ke suia enam tahun, yang merupakan suatu upaya untuk memberikan 
rangsangan pendidian dan menstimulasi perkembangan anak. Penelitian ini sesuai dengan teori dari Santrock (2009) mengemukakan pendidikan anak usia dini merupakan dimensi yang penting bagi perkembangan anak, karena pendidikan anak usia dini (PAUD) mempunyai standar pembelajaran serta kurikulum-kurikulum atas sejumlah landasan yang mampu memberikan dasar-dasar untuk membantu mengembangkan potensi-potensi yang ada didalam diri anak, agar anak bisa menjadi manusia yang berkualitas.

\section{Perkembangan emosi}

Hasil penelitian perkembangan emosi anak mengikuti PAUD didapatkan kemungkinan ada masalah 21 orang $(58,3 \%)$, tidak terdapat masalah 15 orang (41,7\%). Yusuf (2016) dan Tirtayani, Asril \& Wirya (2014) mengatakan bahwa masalah perkembangan emosi anak usia prasekolah yang sering muncul yaitu perilaku membangkang, agresif, ketakutan (Shynes,, Embarrassment dan Anxiety), lemahnya afeksi. Banyaknya permasalahan yang sering terjadi pada anak sehingga dibutuhkan orang tua atau tenaga pendidik untuk memberikan stimulasi yang baik dalam perkembangan emosi anak. Sejalan dengan teori Erikson (2010) mengatakan sarana utama pendidikan anak usia dini (PAUD) adalah memperingatkan dan meningkatkan rasa malu individu anak, anak-anak dibiarkan berteriak marah-marah serta memukul teman merupakan perilaku yang buruk. Rasa malu didintensifikasikan khususnya pada anak yang sering menunjukkan perilaku buruk, perilaku buruk tidak hanya berteriak dan memukul, namun mementingkan diri sendiri, mencari keuntungan dengan merugikan orang lain, bersaing dengan cara tidak baik juga merupakan perilaku perbuatan yang buruk, sehingga para pendidik di PAUD berupaya dalam menanamkan rasa malu serta mengajarkan cara bersikap dengan baik terhadap anak prasekolah.

\section{Perkembangan anak tidak mengikuti PAUD}

\section{Perkembangan sosial}

Hasil penelitian perkembangan sosial anak tidak mengikuti PAUD sedang 31 orang $(86,1 \%)$, tinggi 5 orang $(13,9 \%)$. Dari data tersebut dapat kita lihat bahwa perkembangan sosial tidak mengikuti PAUD mayoritas sedang. Sejalan dengan penelitian Septian, Widyaningsih \& Igomh (2016), mengatakan anak yang tidak mengikuti PAUD menunjukkan belum tercapainya perkembangan sosial dengan baik, karena anak tidak PAUD lebih sering berada dilingkungan rumah serta cenderung melakukan aktivitas dibantu orang tua ataupun pengasuh, sehingga anak mendapatkan perlakuan yang sangat manja. Orang tua juga cenderung membiarkan anaknya berkembang apa adanya, bahkan sebagian orang tua lebh suka anaknya berada/bermain didalam rumah saja, tanpa menstimulasi anaknya untuk belajar bersosialisasi diluar rumah atau bermain dengan anak yang lainnya, tanpa disadari hal tersbut bisa berdampak pada 
perkembangan sosial anak. Kusbiantoro (2015) mengatakan dalam perkembangan anak, terdapat masa kritis pada anak sehingga sangat membutuhkan rangsangan dan stimulasi yang baik agar dapat mebantu mengembangkan potensi yang baik pula. Untuk mendeteksi atau memberikan stimulasi dengan baik secara menyeluruh dan terkoordinasi dapat diselenggarakan dalam bentuk kemitraan serta kerjasama antara keluarga dengan tenaga, Kesehatan, sosial dan Pendidikan anak usia dini (PAUD).

\section{Perkembangan emosi}

Perkembangan emosi anak dengan sampel 36 responden yang tidak mengikuti PAUD didapatkan, kemungkinan ada masalah 23 orang $(63,9 \%)$ tidak terdapat masalah 13 orang $(36,1 \%)$. Orang tua merupakan pendidik pertama dan utama bagi anak dan mempunyai pernan penting dalam perkembangan emosi anak. sebagai orang tua harus memberikan contoh dalam berperilaku dan mengatasi konflik-konflik dengan baik dihadapan anak. Ketika orang tua atau lingkungan sekitar tidak bisa memberikan contoh dengan baik akan berpengaruh terhadap anak. Orang tua menyelesaikan konflik dengan bertindak kasar dan bertengkar dihadapan anak, anak akan merekam semua perbuatan orang tua sehingga anak akan melakukan hal yang sama ketika anak berada pada situasi yang sama (Jahja, 2011).

Sejalan dengan penelitian Primana \& Putri (2018), mengatakan orang tua lebih memberi peringatan terhadap anak untuk tidak marah karena malu akan penilaian dari masyarakat tanpa memberikan contoh dalam bersikap, orang tua kurang mengerti dalam memberikan stimulasi emosi terhadap anak. Sesuai teori Santrock (2011) mengatakan orang tua lebih banyak mengajarkan anaknya dalam menunjukkan emitional reserve dari pada emitonal expressivity. Anak-anak lebih sering dialihkan perhatiannya oleh orang tua dibanding dengan memberikan kesempatan untuk mengenali dan menggali cara menghadapi persaan emosi tersebut. Ketika orang tua mampu memberikan contoh serta melatih anak dalam mengekspresikan emosi dengan baik serta menstimulasi perkembangan emosi anak sesuai dengan kebutuhan perasaan anak maka perkembangan anak akan lebih baik.

\section{Perbandingan sosial anak mengikuti dan tidak mengikuti PAUD}

Hasil penelitian yang dilakukan di TK N Pembina 3 pekanbaru, perbandingan perkembangan sosial anak mengikuti dan tidak mengikuti PAUD, dengan jumlah responden 36 mengikuti dan 36 tidak mengikuti, dengan menggunakan uji statistik non-parametrik Mann Whitney test didapatkan dengan nilai $P_{\text {value }} 0,000$ (<0,05). Sehingga dapat disimpulkan, Ha diterima yang berarti terdapat perbedaan perkembangan sosial anak mengikuti dan tidak mengikuti PAUD. Penelitian ini sejalan dengan penelitian Lisardika (2017), dengan hasil penelitian peroleh $P_{\text {value }}$ 
$0,000<0,05$ yang artinya terdapat perbedaan yang signifikan kematangan sosial antara anak mengikuti dan tidak mengikuti Taman Penitipan Anak (TPA), terlihat pada anak pernah mengikuti tempat penitipan anak lebih cepat mengembangkan kemampuannya seperti beradaptasi dengan lingkungan. Penelitian yang dilakukan oleh Wulandari (2009), dengan hasil yaitu terdapat perbedaan yang signifikan pada kematangan sosial anak yang mengikuti playgroup dan tidak mengikuti playgroup. Sejalan dengan teori yang dikemukakan oleh Hurlock (2011) anak yang mengikuti pendidikan di usia dini akan melakukan penyesuaian sosial dengan baik dibandingan anak yang tidak melakukan pendidikan usia dini.

\section{Perbandingan emosi anak yang mengikuti dan tidak mengikuti PAUD}

Hasil penelitian yang dilakukan di TK N Pembina 3 pekanbaru, menggunakan uji statistik Mann Whitney test dengan sampel 36 mengikuti dan 36 tidak mengikuti PAUD. Didapatkan dengan nilai $P_{\text {value }} 0,040(<0,05)$. Sehingga dapat disimpulkan Ha diterima yang artinya terdapat perbedaan perkembangan emosi anak yang mengikuti dan tidak mengikuti PAUD.

Sejalan dengan Tirtayani, Asril \& Wirya (2014) mengatakan lingkungan pendidikan dapat membantu anak-anak dalam perkembangan emosi dan kepribadiannya dalam suatu kesatuan, ketika tenaga pendidik mampu menjalin hubungan yang harmonis dengan murid. Sejalan penelitian Siregar (2011) mengatakan kualitas pendidikan anak usia dini merupakan kunci keberhasilan dalam melaksanakan peranannya. Perkembangan emosi anak dapat berkembangan dengan baik melalui pendidikan anak usia dini ketika tenaga pendidikan mampu memberikan pendidikan dan pengasuhan sesuai dengan apa yang anak butuhkan.

Penelitian Nurjannah (2017) mengatakan kecerdasan emosional pada anak usia dini tidak dimiliki anak secara alami, tetapi harus ditumbuhkan serta dikembangkan. Selain orang tua, PAUD dapat membantu mengembangkan aspek emosi anak usia dini memalui pembelajaran serta kurikulum yang mengacu pada penggalian potensi anak.

\section{SIMPULAN}

Berdasarkan hasil penelitian yang yang dilakukan di TK N Pembina 3 Pekanbaru, tentang perbandingan sosial dan emosi anak yang mengikuti dan tidak mengikuti PAUD, dapat diambil kesimpulan sebagai berikut :

a. Karakteristik responden meliputi jenis kelamin anak yaitu laki-laki 37 orang $(51,4 \%)$, perempuan 35 orang $(48,6 \%)$. Usia minimum 5, maksimum 6 , dengan nilai mean $=58,5$. jumlah saudara sedikit (1-2) 40 orang $(55,6 \%)$, banyak (>2) 32 orang $(44,4 \%)$. Pekerjaan orang tua PNS 10 orang (13,9\%), Guru 5 orang (6,9\%), Wiraswasta 24 orang $(33,3 \%)$, Pegawai 10 orang (13,9\%), IRT 23 orang $(31,9 \%)$. 
b. Perkembangan sosial anak mengikuti PAUD sedang 17 orang (47,2\%), tinggi 19 orang $(52,8 \%)$.

c. Perkembangan emosi anak mengikuti PAUD kemungkinan ada masalah 21 orang $(58,3 \%)$, tidak terdapat masalah 15 orang $(41,7 \%)$.

d. Perkembangan sosial anak tidak mengikuti PAUD sedang 31 orang $(86,1 \%)$, tinggi 5 orang $(13,9 \%)$.

e. Perkembangan emosi anak tidak mengikuti PAUD kemungkinan ada masalah 23 orang $(63,9)$, tidak terdapat masalah 13 orang $(36,1 \%)$.

f. Perbandingan sosial anak mengikuti dan tidak mengikuti PAUD didapatkan hasil $P_{\text {value }}$ $0,000(<0,05)$ yang berarti terdapat perbedaan.

g. Perbandingan emosi anak mengikuti dan tidak mengikuti PAUD didapatkan hasil $P_{\text {value }}$ $0,040(<0,05)$ yang berarti terdapat perbedaan.

\section{DAFTAR PUSTAKA}

Aghnaita, A. (2018). Perkembangan fisik-Motorik anak 4-5 tahun (kajian konsep perkembangan anak).

Al-Athfal : Jurnal pendidikan Anak, 3(2), 219.

Anggraini, H. \& Emmanuel, S. (2016). Hubungan kelekatan dengan kecerdasan emosi dan penyesuaian sosial pada anak usia dini. Jurnal pedagogi, 2(3).

Al Khudri, S., Heleni, F., Sean, M, E. (2017). Persepsi orang tua terhadap pemecahan masalah temper tantrum anak usia dini. Jurnal pendidikan 3(1), 111-115.

Ashary, Y., Rahamma, T., \& Fatimah, J. M. (2015). Pengendalian perilaku emosional anak TK melalui komunikasi antara guru dengan orang tua. Jurnal komunikasi kareba 4(4), 415-434.

Badan Pusat Statistik Kota Pekanbaru. (2017). Data anak usia prasekolah. Kota Pekanbaru 2017.

Erikson, E. H. (2010). Childhood and societ. Yogyakarta : Pustaka Pelajar.

Fajarini, F., Khaerani, N. M. (2014). Kelekatan aman, religiusitas, dan kematangan emosi pada remaja. Jurnal psikologi integratif, 2(1), 22-29.

Hull, D., \& Johnston, D. I. (2008). Dasar-dasar pediatri. Jakarta : EGC.

Hurlock, E. B. (2011). Psikologi perkembangan : suatu pendekatan sepanjang rentang kehidupan. Jakarta : Erlangga.

Jahja, Y. (2011). Psikologi perkembangan. Jakarta : Kencana.

Kemenkes RI. (2017). Profil kesehatan indonesia 2016. Keputusan menteri kesehatan Indonesia RI. Jakarta.

Kusbintaro, D. (2015). Pertumbuhan dan perkembangan anak usia prasekolah di TK aba 1 lamongan. Jurnal pendidikan usia dini.7(1) 
Lisardika, A. A. (2017). Perbedaan kematangan sosial anak usia dini ditinjau dari keikutsertaan di taman penitipan anak (TPA). Jurnal psikologika, 22(1).

Musyarofah. (2017). Pengembangan aspek sosial anak usia dini di taman kanak-Kanak. Journal of communication 2(1), 99-121.

Nurmalitasari, F. (2015). Perkembangan sosial emosi pada anak usia prasekolah. Jurnal Psikologi 23(2).

Nurhabibah., Ahmad, A., \& Madiyah, E. (2016). Perkembangan sosial emosional anak melalui interaksi sosial dengan teman sebaya di paud. Jurnal pendidikan usia dini 1(1):60-67.

Nurwianti, A. (2015). Ketidakberminatan orang tua tehadap program paud. Jurnal pendidikan anak usia dini, 3(2)32-38.

Primana, L., \& Putri, C, I. (2018). Gambaran perilaku disregulasi emosi anak prasekolah. Jurnal psikologi 6(10).

Rekawati, S., Nursalam., \& Sri, U. (2013). Asuhan keperawatan bayi dan anak. Ed.2. Jakarta : Salemba medika.

Santrock, J. W. (2009). Perkembangan anak. Jakarta : Erlangga.

Septiani, R., Widyaningsih, S \& Igomh, M, K. (2016). Tingkat perkembangan anak usia prasekolah. Jurnal keperawatan 4(2), 114-125.

Siregar, N. M. (2011). Kemampuan tenaga pendidik dalam meningkatkan kebugaran anak usia dini. Jurna pendidikan anak, 7(1).

Susanto, A. (2011). Perkembangan anak usia dini. Jakarta : Kencana.

Tirtayani, L. A., Asril, N. M., \& Wirya, I. N. (2014). Perkembangan sosial emosional pada anak usia dini. Yogyakarta : Graha Ilmu.

Wulandari, A. (2009). Perbedaan kematangan sosial anak ditinjau dari keikutsertaan pendidikan prasekolah (playgroup). Jurnal Biomedika $8(1)$. 